\section{TRABALHO E CONHECIMENTO ESTÉTICO}

WORK AND AESTHETICAL KNOWLEDGE

Ronaldo Rosas Reis 1
Resumo Este ensaio busca expor o conceito 'corpo trabalhador' e desenvolver uma reflexão crítica sobre o princípio educativo da estética e a origem do conhecimento artístico apreendido na teoria marxista como forma de contribuição para os estudos desenvolvidos na área de Trabalho e Educação, na qual identificamos uma lacuna quanto à questão estética como elemento de problematização da história cultural do trabalhador. A partir desta análise, o texto apresenta as principais demandas ideológicas e metamorfoses conceituais da teleologia burguesa da arte e do ensino de arte no Brasil nos documentos oficiais da legislação educacional brasileira mais recente.

Palavras-chave corpo trabalhador; educação estética; pós-modernismo; arte brasileira; ensino de arte.
Abstract This essay attempts to examine the concept "working body" and develop a critical reflection about the educational principle of aesthetics and the origin of artistic knowledge, understood in Marxist theory as a contribution to the studies developed in the areas of Work and Education. In our view, these studies fail to consider the aesthetical issue as one of the elements in the cultural history of the worker. On the basis of this analysis, the text presents the main ideological demands and conceptual changes of the bourgeois teleology of art and of the teaching of art in Brazil in the official documents of the most recent Brazilian legislation on education. Key words working body, aesthetical education; post-modernity; Brazilian art; teaching of art. 


\section{Introdução}

O presente ensaio está dividido em duas partes, cada uma correspondendo a motivações teórico-políticas complementares. Ele procura atender tanto a uma necessidade específica de aprofundar as investigações que venho realizando em torno do pensamento estético de Marx quanto à exigência de ampliação do debate crítico sobre a economia política da cultura no Brasil. Para atender à primeira motivação, procurei sistematizar parte dos estudos teóricos que venho desenvolvendo, com o apoio do $\mathrm{CNPq}$, no âmbito da pesquisa "Pós-modernismo, globalização e a formação estético-cultural do trabalhador urbano no Rio de Janeiro". Do ponto de vista metodológico, o horizonte da pesquisa é a organização de um corpus teórico sobre a relação trabalhocultura no sentido de oferecer uma contribuição aos estudos correntes sobre trabalho-educação. Em que pese a pesquisa se encaminhar para o seu primeiro ano de realização, e já tendo recolhido elementos empíricos para um primeiro 'vôo' analítico à luz da teoria estética marxiana, penso que seria demasiado prematuro considerá-lo como um 'resultado', ainda que parcial, da pesquisa mencionada. Portanto, permito-me encarar a realização deste ensaio como uma oportunidade para testar algumas das idéias aqui expostas.

Já para atender à segunda motivação, procurei recuperar um conjunto de reflexões críticas desenvolvidas em trabalhos anteriores sobre a teleologia burguesa da arte e do ensino de arte no Brasil, mediante as quais procuro identificar as suas principais demandas ideológicas e metamorfoses conceituais. Tais trabalhos - alguns publicados e outros inéditos - compõem em linhas gerais o eixo das investigações sobre a economia política da cultura no Brasil que venho realizando há quase duas décadas.

Para finalizar, esclareço que a menção anterior sobre a motivação teórico-política complementar de cada parte deste ensaio leva em consideração, sobretudo, a importância dos temas abordados nessa segunda parte. Na realidade, no campo de trabalho e educação, são raros os estudos educacionais que têm incorporado a questão estética a esse binômio como elemento de problematização da história cultural do trabalhador, e quando o fazem é apenas perifericamente. Em contrapartida, já vêm de longe os estudos filosóficos, estéticos e de história da arte que buscam identificar o fundamento da educação na relação da arte com o mundo do trabalho.

A constatação dessa lacuna não traz, contudo, qualquer conotação crítica a um improvável desconhecimento ou desprezo dos educadores pela importância da formação estético-cultural do trabalhador na apreciação das relações trabalho-educação. Muito pelo contrário, conforme prevê o eixo norteador do campo de confluência trabalho e educação do Programa de Pós-Graduação em Educação da Universidade Federal Fluminense, que orienta a linha de pesquisa "O mundo do trabalho e a formação humana", 
“é a crítica à economia política que conduz a uma visão histórica da relação trabalho e educação, onde se busca compreender e reconstruir, ao nível do discurso, as diferentes mediações constitutivas dessa relação" (Franco, Rodrigues e Frigotto, 2000), estimulando-se, a partir delas, investigações variadas, tais como

“o mundo do trabalho em imagens e a fotografia como fonte histórica; formação humana, técnica e profissional; as reformas do ensino médio e técnico; o pensamento pedagógico dos empresários: trabalho, educação e cultura; educação dos trabalhadores; movimento sindical, cultura e educação; cultura, educação e comunicação; trabalho e meio ambiente; e as iniciativas de economia popular" (Franco, Rodrigues e Frigotto, 2000).

Assim, dado o notável recente despertar dos principais agentes do capitalismo tardio - empresários, governantes, políticos e educadores neoliberais - para o tema, impõe-se à agenda política do campo democrático uma atitude investigativa mais firme e incisiva.

\section{O 'corpo trabalhador' e o princípio educativo da estética em Marx}

Minha consciência é minha relação com o que me cerca. Marx e Engels (2000)

Ao formular a idéia de que as coisas e o pensamento formam uma totalidade indissociável, Alexander Baumgarten, em 1750, abalaria profundamente as bases do pensamento estético europeu. Até então, apartados pela miopia da filosofia clássica, os sentidos e o espírito humano encontrariam, na Estética do eminente pensador alemão2, o caminho da reconciliação.

A partir daí, um duplo movimento ganharia impulso no cenário cultural da Europa. Num sentido mais geral, a busca da autonomia da estética diante da filosofia seria impulsionada por algumas das diversas correntes libertárias presentes no pensamento romântico na passagem do século XVIII para o XIX ${ }^{3}$. De um modo mais específico, o impulso se daria no sentido inaugural da moderna tradição de ruptura da arte moderna. A despeito disso, as formulações originais de Baumgarten assumiriam, quase um século depois de publicadas, a feição de algo próximo a uma "anestética", tal o modo como foram descaracterizadas tanto pelo idealismo como pelo positivismo, então dominantes no romantismo alemão (Eagleton, 1993) 4 .

Em meados do século XIX, com a disseminação do pensamento de Hegel para além das fronteiras da Alemanha, um novo marco de abordagem dos problemas estéticos e da arte seria estabelecido. A principal inovação intro- 
duzida por Hegel no debate filosófico de sua época foi a idéia de que sendo a realidade apreendida, pensada e explicada pela Razão, ela não passaria de uma 'representação de um discurso estético', um 'artefato cultural' por meio do qual a Vontade Coletiva, a Moral, o Direito, a Política do burguês se expressam (Eagleton apud Reis, 2003). Nesse sentido, o caráter inovador do seu pensamento estético correspondia, sobretudo, à percepção que arquitetos e desenhistas industriais tinham da importância do progresso técnico e do surgimento de novos materiais para a experimentação e o desenvolvimento de formas estéticas autônomas em relação às normas e à linguagem então vigentes. Para estes artífices modernos, era fundamental transformar a indiferença da mentalidade burguesa face aos impulsos vitais de uma sociedade em progresso, seja abolindo o ornamento inútil seja impondo como contrapartida a este o ferro, o concreto, o vidro e outros materiais como elementos a um só tempo estruturantes e expressivos (Argan apud Reis, 2003).

Deve-se notar, a esse propósito, que a extinção dos últimos laços que prendiam a burguesia ao ancien régime se tornara um problema para os novos-ricos, à medida que a ausência de referência do gosto refinado da velha classe aristocrática lhes dificultava a busca de um modelo estético que refletisse a sua riqueza. Em contrapartida, a Academia - a grande obra do Iluminismo burguês — há muito deixara de ser uma fonte confiável para inflexões estéticas inovadoras - como foram às obras de Jean-Louis David e de Éugène Delacroix - , cedendo espaço para uma crescente e definitiva cultura academicista, repleta de regras e normas que primavam pela inexpressividade e falta de originalidade. Sem referências, uma parcela significativa e influente da burguesia passaria a adotar tudo que se revelava ostentatório, pomposo e dispendioso, sentindo-se à vontade para projetar no espaço público, na cidade, a sua visão particular de mundo (Sennett apud Reis, 2002a).

Entretanto, se não restam dúvidas que a estética de Hegel representou um significativo passo em direção à compreensão científica do fenômeno artístico, não menos verdadeiro é o fato de que o seu esquematismo conceitual acabaria subordinando a arte a uma "fantástica Idéia Absoluta" (Konder, 1967). Dito de outro modo, ao não levar em conta a atividade real humana como práxis, isto é, ao não apreender a realidade como atividade humana sensorial objetiva, a estética hegeliana limitou-se a descrever o mundo sensível de forma contemplativa.

Coube a Marx, a partir de 1844, retomar as bases da estética baumgartiana, com a tarefa de fazer avançar a reabilitação dos sentidos na história humana. Nesse sentido, grande parte das análises críticas que realizou sobre os problemas estéticos foi dedicada a lançar as bases de uma historicização da sensibilidade. Partindo disso, Marx reconheceria a estética como um fundamento essencial do conhecimento humano, vendo nela o princípio educativo que permitiu o nascimento das artes. 
Nos seus escritos econômicos e filosóficos, Marx aborda o caráter histórico e social da sensibilidade interpondo a dialética materialista à estética idealista de Hegel. Observando as contradições geradas a partir dos conflitos entre as forças produtivas e as relações sociais de produção, Marx apreende que o esteticismo exagerado da classe burguesa e o brutal ascetismo da sociedade capitalista compõem as duas faces de uma mesma moeda. Na concepção marxiana, a realidade capitalista é hostil à plenitude do desenvolvimento da capacidade humana de criar. E embora Marx insistisse que de forma alguma isso se constituísse num impedimento à criação literária e artística, da mesma forma ele insistiria que

“toda essa podridão só nos dá um resultado: (...) o conflito, pois pela divisão do trabalho, acontece efetivamente que a atividade intelectual e a atividade material - o gozo e o trabalho, a produção e o consumo - acabam sendo destinados a indivíduos diferentes" (Marx e Engels, 2002, p. 26-27).

A ignorância do papel preponderante do trabalho na vida humana e as contradições daí decorrentes são, para Marx, um dos aspectos que o levaram a criticar as concepções estéticas de Hegel. De acordo com essa crítica, o idealismo hegeliano não percebe ou finge não perceber que o indivíduo, sob o capitalismo, cria fantasmagorias acerca da sua própria representação no mundo. Da mesma, ao isolá-lo no interior da Razão, ou Idéia Absoluta, o idealismo hegeliano isola-o igualmente da relação com a natureza e do trabalho de transformá-la. Portanto, de acordo com essa concepção estética, o indivíduo é levado a se apreender como um ser autocriador, estetizado pelas suas próprias experiências estéticas. Ao desconsiderar a essencialidade do trabalho na vida humana, esse indivíduo 'feito por si mesmo' somente pode conceber a sociedade de maneira contemplativa e crescentemente desumanizada (Marx e Engels, 2002). No sentido contrário, Marx dirá que a existência de uma relação somente se justifica na medida em que ela existe para o próprio sujeito, pois, sendo a consciência um produto social,

“(...) o será enquanto existirem os homens. (...) [a consciência] é, antes de qualquer coisa, apenas a consciência do meio sensível mais próximo e de uma interdependência limitada com outras pessoas e outras coisas situadas fora do indivíduo que toma consciência (...)" (Marx e Engels, p. 25, grifos do autor).

A premissa marxiana de que o processo de humanização, compreendido como objetivo vital do homem para que este desenvolva todas as suas dimensões, se faz no e pelo trabalho, traz incluída a idéia de que o trabalho é também um movimento estético. Para Marx, assim como a razão não deve ser reduzida à esfera das idéias sob o risco de se tornar uma mera abstração lógica 
e/ou uma ideologia, da mesma forma a sensibilidade não deve ser tratada como um fenômeno desprovido de uma materialidade. Segundo Vázquez, Marx compreende que, ao humanizar a natureza por meio do trabalho, os sentidos e o pensamento nascem e se enriquecem nessa relação específica (apud Konder, 1967). Partindo de observações empíricas, Marx chegará a conclusão que

“O homem apropria-se do seu ser universal de uma maneira universal, portanto, como homem total. Todas as suas relações 'humanas' com o mundo, isto é, ver, ouvir, cheirar, ter paladar, tato, pensar, olhar, sentir, querer, agir, amar, em suma, todos os órgãos da sua individualidade, que são imediatos na sua forma enquanto órgãos comuns são, na sua relação 'objetiva', ou seu 'comportamento diante do objeto', a apropriação desse objeto. A apropriação da realidade 'humana', a maneira como esses órgãos se comportam diante do objeto, constitui a 'manifestação da realidade humana'” (Marx e Engels, 1979, p. 23).

A força dessa idéia traz a indicação do empreendimento revolucionário que Marx irá desenvolver no âmbito da estética. A começar por considerar a natureza sensível da linguagem, isto é, "o próprio elemento do pensamento, o elemento da expressão vital do pensamento". Para Marx, a verdadeira ciência é aquela que começa pela natureza, logo, sendo a percepção sensível "uma forma dupla de consciência sensível e necessidade dos sentidos", será ela a base de todo conhecimento científico (Eagleton, 1993, p. 147). Por conseguinte, ele conceberá que a história é o resultado do esforço do corpo humano, "através de suas extensões que chamamos de sociedade e tecnologia, em luta pelo autocontrole dos seus poderes" (Marx apud Eagleton, 1993, p. 147). De acordo com Eagleton, a historicização da indústria realizada por Marx é "frente e verso" de um mesmo fenômeno, mediante o qual as capacidades sensíveis e as instituições sociais podem ser submetidas tanto a uma leitura histórica como a uma leitura fenomenológica. Nesse sentido, a história da indústria é, do ponto de vista do historiador, a expressão da acumulação das forças produtivas, como é, do ponto de vista fenomenológico, a expressão da materialização do corpo humano, "o livro aberto dos poderes essenciais do homem" (Eagleton, 1993, p. 151).

Assim, ao tomar a sensibilidade como um elemento imanente ou fundador do próprio corpo, portanto, como constituinte inaugural de "todo o conhecimento", segundo as suas próprias palavras, Marx não apenas promoveria uma reabilitação da percepção sensível ou sensorial, como promoveria também uma revalorização do conhecimento artístico (Konder, 1967). De acordo com Marx,

“os sentidos do homem social são diferentes dos do homem que não vive em sociedade. Só pelo desenvolvimento objetivo da riqueza do ser humano é que a riqueza 
dos sentidos humanos subjetivos, que um ouvido musical, um olho sensível à beleza das formas, que numa palavra, os sentidos capazes de prazeres humanos se transformam em sentidos que se manifestam como forças do ser humano e são, quer desenvolvidos, quer produzidos. (...) A formação dos cinco sentidos representa o trabalho de toda a história do mundo até hoje" (Marx, 1979, p. 24-25, grifos do autor).

Não obstante, Marx esclarece que tal ponto de vista não encerra uma tendência à mistificação da percepção sensível. Conforme assinalei anteriormente, o sucesso alcançado pela estética hegeliana se deveu, sobretudo, ao arejamento libertário que ela proporcionou aos artistas e artífices burgueses da sua época. A despeito disso, o conjunto da obra de Hegel reservaria um papel menor para o conhecimento artístico, na medida em que a sua função seria a de preparar a sensibilidade humana para a compreensão do conhecimento filosófico pleno. Por sua vez, ao reconhecer a sensibilidade como um elemento imanente ou fundador do próprio corpo, Marx valorizaria o conhecimento artístico vinculando-o, contudo, à exigência da consciência teórica. Ao fazer isso, nota Fredric Jameson (1985), Marx evita transferir para a arte a condição de "coruja de Minerva", atribuída à filosofia por Hegel5.

De acordo com Scarry (apud Eagleton, 1993), Marx apreende que o mundo construído se apresenta, desde as formações sociais primitivas às mais complexas, como uma metáfora materializada do corpo trabalhador, no qual o sistema de produção econômica representa o elemento que rege o processo de descorporificação e espiritualização de homens e mulheres. Com efeito, sendo a percepção sensível a estrutura constitutiva da prática humana, a propriedade privada não poderia deixar de ser a 'expressão sensível' da alienação do homem em relação ao seu próprio corpo. E, na medida em que a plenitude sensível do indivíduo é reduzida ao impulso único de possuir, isto é, na medida em que a plenitude corpórea de homens e mulheres é reduzida ao simples ato de suprir as suas necessidades elementares, faz sentido afirmar a ocorrência, nesse nível, de uma ruptura da vida sensível.

É preciso aprofundar, no entanto, o caráter geral e específico dessa ruptura. Segundo Marx, se em qualquer circunstância a alienação do produto e do meio criativo que o produziu é uma decorrência da atividade exercida pelo trabalhador, sob o capitalismo isso se torna, para este último, duplamente um problema. Não apenas porque o produto do seu trabalho não lhe pertence, mas também porque a sua criatividade é reificada sob a forma de mercadoria como força de trabalho. Nessa condição, Marx dirá que o regime da propriedade privada expressa sensivelmente a alienação do homem sobre seu próprio corpo, projetando a vida sensível (ou realidade corpórea) em direções antitéticas.

Numa direção se encontra o corpo ocioso do desocupado das elites que, sem qualquer necessidade de sobrevivência, aliena-se da vida sensível, per- 
cebendo-se um aleijão. Sua vantagem sobre o corpo trabalhador, segundo Eagleton (1993, p. 149), é que o seu dinheiro "recupera vicariamente a sua sensibilidade alienada pelo poder do próprio capital", ainda que isso resulte num "corpo fantasma", um "alter ego zumbi a recolher satisfações de segunda mão".

Tomando como exemplo a vertiginosa expansão do capitalismo no curso do século $\mathrm{XX}$, nada menos surpreendente é a simetria verificada na relação entre o crescimento e a valorização da subjetividade e a estetização do dinheiro. Ao ponto de, nas condições atuais do capitalismo tardio, os desejos imaginários do parasita social e o dinheiro se constituírem num fenômeno puramente estético. A despeito disso, seria por demais ingênuo creditarmos ao comportamento individual do homem burguês a responsabilidade dessa "divisão traumática do corpo humano entre o materialismo bruto e o idealismo caprichoso" (idem). Fosse isso verdadeiro, estaríamos desconsiderando, por exemplo, a importância histórica das tensões provocadas pela produção artística de indivíduos burgueses que se colocaram contra o próprio estatuto da arte burguesa na primeira metade do século XX. Penso, por exemplo, na inegável contribuição que artistas como Picasso, Kandinsky, Malevitch e Max Ernst deram no sentido da transformação das linguagens da arte à frente dos principais movimentos artísticos do primeiro quarto do século XX, dentre eles, o cubismo, o construtivismo russo e o surrealismo.

É bem verdade que, conforme analisei em trabalho anterior6, a capacidade da burguesia de absorver e neutralizar as contestações ao seu estatuto decorre da sua igual capacidade de adaptar o seu telos às novas demandas geradas nas relações sociais de produção. Note-se, nesse sentido, que, ao impregnarem de negatividade a arte burguesa - " "a verdade é uma mentira, a moral fede e a beleza é uma merda", diziam as vanguardas modernistas (Eagleton, 1993, p. 268) — os artistas revolucionários não apenas acabariam contribuindo para o surgimento de novos procedimentos artísticos e críticos, que por sua vez acabariam incorporados ao telos da burguesia, como também acabariam contribuindo para a extraordinária estetização da subjetividade do homem contemporâneo. Assim, impregnada, a subjetividade dos múltiplos e diversos movimentos sociais em evidência nos anos 50 e 60 (beatnik, hippie, direitos civis, black-power, feministas, estudantis, operários etc.) reivindicaria "a valoração do saber, do trabalho intelectual e da criatividade", em oposição à organização disciplinar do modelo capitalista industrialista (Hardt e Negri, 2001, p. 294-295).

A outra direção para onde se dirige a vida sensível é aquela na qual se encontra o corpo trabalhador. Devastado pela necessidade de sobrevivência, esse corpo percebe-se limitado pela fronteira da monotonia, da repetição, em suma, anestesiado 7 dos seus próprios sentidos, o trabalhador transforma seus 'impulsos' criativos em 'instintos'. Em outras palavras, se no ní- 
vel da existência sensorial o indivíduo se encontra em condições de transcender suas próprias limitações mediante a utilização da sua criatividade, sob o regime histórico da propriedade privada e da exploração do trabalho assalariado, o indivíduo se encontra "cegamente biologizado" (Eagleton, 1993, p. 149). Nas palavras de Marx,

“O 'sentido' sujeito às necessidades práticas vulgares não passa de um sentido 'limitado'. (...) O homem cheio de preocupações, necessitado, não tem sentidos para o mais belo espetáculo. O comerciante de minérios apenas atende ao valor comercial dos minérios, não se apercebe da beleza, nem da natureza particular do mineral; não tem o sentido mineralógico" (Marx e Engels, 1979, p. 25).

Pode-se argumentar, a título de contraposição, que o próprio Marx, embora considerasse o ambiente capitalista hostil à criatividade, não via nele um impedimento para o trabalhador criar/fruir esteticamente. Inúmeros autores marxistas têm salientado, com razão, que desde o final do século XIX, a indústria do entretenimento de massa tem sido pródiga em nos fornecer indicadores da criatividade e do crescente interesse e participação da classe trabalhadora nos espetáculos artísticos. Do cinema à música popular e mesmo à televisão, uma extraordinária quantidade de artistas, músicos, dançarinos, escritores, etc., oriundos da classe trabalhadora, marcaram e continuam marcando presença no mundo do espetáculo. Da mesma maneira, é notável a projeção alcançada por gêneros, ritmos musicais e danças, como o jazz, o rock, o samba etc., oriundas do mundo do trabalho e das classes populares, bem como o envolvimento e a participação destas em espetáculos artísticos de massa. Como sublinha ironicamente Hobsbawm (1991, p. 37), em que pese toda negatividade produzida pela indústria do entretenimento, constitui um fato extraordinário que ela não tenha conseguido até hoje "fazer do público um bando de idiotas".

Decerto que não. Todavia, nunca é demasiado salientar que, ao fazer referência a um progressivo embrutecimento dos sentidos do corpo trabalhador, a teoria marxiana não perde de vista a correspondência entre o grau de desenvolvimento alcançado pelas forças produtivas e o grau de desenvolvimento alcançado pela divisão do trabalho (Marx e Engels, 2002). Nesse sentido, se a história traduz a luta do homem pelo autocontrole da sua sensibilidade, tudo o que lhe é extensivo, da sociedade à tecnologia, se impõe como uma dualidade a ser superada, como uma forma de recuperar os poderes que lhe foram pilhados. A literatura e o cinema têm sido pródigos na abordagem dessa dualidade e do esforço humano para superá-la. Dentre os exemplos que me ocorrem, cito o clássico Tempos Modernos (1931), de Charlie Chaplin, no qual ele descreve e situa o corpo trabalhador como extensão da maquinaria na grande indústria. Da mesma forma, o filme Metrópolis (1929), de Fritz 
Lang, explora histórica e fenomenologicamente o processo de expropriação dos sentidos do corpo trabalhador. E a maioria das obras de ficção científica do escritor norte-americano Philip K. Dick, como Blade Runner (1977), Total Recall (1992) e Minority Report (2001), todas levadas ao cinema, apresentam personagens (ciborgues) com características de uma modulação sofisticada do trabalhador expropriado do seu corpo próprio. Finalmente, apenas como lembrança de uma referência teórica já clássica, Walter Benjamin (1985), no ensaio A obra de arte ao tempo de sua reprodutibilidade técnica (p. 165-196), ao analisar a problemática da 'aura', chama a atenção para diferentes níveis de alienação produzidos pelo "efeito de distração" no cinema.

Não por acaso Kosik (1995) destaca na teoria marxiana uma nova definição para o corpo trabalhador reificado a partir da superação da dualidade entre o prático e o estético. Da mesma forma, ele destacará que tal definição constitui o ponto de partida da educação estética na perspectiva marxiana. Com efeito, ao analisar o caráter ontocriador da práxis transformadora da natureza, Kosik observará que a reificação é tanto um produto histórico como forma de prática social. Depreende-se daí que a história das manifestações humanas de alegria, júbilo, tristeza e dor expressadas artisticamente, é a história da práxis criadora, a conferir à realidade humano-social seu traço universal, isto é, "formador e, ao mesmo tempo, forma específica do ser humano" (Kosik, 1995, p. 221-222)8.

É bem verdade que, ao elaborar dessa forma o princípio educativo da estética, Marx desenha uma perspectiva moral para a arte, o que o leva à proximidade do modelo educacional observado na estética de Schiller. Como nota Jameson, se Schiller tinha em mente particularmente a oferta de uma arte nacional com a finalidade de educar esteticamente a burguesia alemã, garantindo-lhe assim a "sua unidade e autonomia políticas" (1985, p. 75), Marx fará disso um modelo educacional universal. Da mesma forma, Eagleton (1993, p. 81) nota que tanto para Schiller como para Marx a estética era "a força que está na base de nossa humanidade moral", capaz de reformar a cultura e revolucionar a subjetividade.

É bem verdade também, a partir dessas considerações, que, no atual estágio de desenvolvimento capitalista, cuja complexidade pode ser avaliada pelos inúmeros e diversos níveis de mediação existentes na relação entre o processo histórico-social e o existencial-individual, muitos autores buscam justificar moralmente a profunda estetização da vida social. Muito embora o tema exija uma atenção maior de nossa parte, não tenho a pretensão de desenvolvê-lo no momento. Gostaria apenas, no entanto, de sugerir que tal justificativa não apenas parte de uma visão de mundo na qual a especificidade do sensível tem sido pensada como um culto da minoria, como também objetiva mascarar o fato que, depois da arte, a própria sensibilidade adquiriu um valor de troca. Trata-se de uma visão do tipo pós-estruturalis- 
ta e do tipo autodenominado 'politicamente correto' que, para promover a estetização do pensamento, esforça-se em desacreditar o papel vital da verdade como referência para se examinar o telos da história, o que não é exatamente o caso aqui. Muito pelo contrário, pois, para Marx, a importância da educação estética se situa na medida em que ela pode emergir da tensão historicamente produzida entre o real e o possível.

Permito-me deduzir, portanto, considerando, sobretudo, as transformações de base ocorridas no pós-modernismo, que a reflexão de Marx, ao abarcar o universo de motivações psicológicas e morais que co-determinam, ao lado relações sociais de produção e da luta das forças econômicas contra o modo de produção dominante, procura dar-lhes uma significação verdadeiramente humana. Vejo, por fim, na idéia marxiana que "o estético só poderá florescer em virtude da transformação política", atravessar a modernidade de ponta a ponta, e, no limite, chegar ao pós-modernismo exigindo dos trabalhadores o cuidado - ou a atenção se se preferir - redobrado com a construção de sua identidade.

Eu me sentiria frustrado de escrever um texto sobre a produção do conhecimento estético na teoria marxiana se não pudesse retomar as críticas que há anos venho fazendo sobre a arte e o ensino de arte no Brasil. Gostaria, assim, de dar continuidade ao presente ensaio reincidindo sobre esse tema em dois tempos, antecipando que parte dos argumentos aqui expostos já foi publicado em outros trabalhos e debatido em alguns fóruns de educação.

\section{Arte, legitimidade social e realidade brasileira}

Vem de longe a constatação de que, no Brasil, a arte não detém legitimidade social. Decorre daí que uma obra de arte produzida em nosso país seja ela uma escultura, um desenho, uma pintura, se 'desmancha no ar'. Dito de outro modo, antes de a obra estar no museu, na casa, na galeria, está em lugar nenhum: "nasceu para desaparecer" (Venâncio Filho, 1980, p. 23).

É verdade que, sob o capitalismo, a crise da arte não foge aos padrões estruturais do que é próprio ao sistema no qual ela se origina e que a abriga. Nesse sentido, a contradição permanente em que ela se encontra é tanto representativa do esforço das forças produtivas empenhadas na sua transformação como expressão das relações sociais de produção presentes nesse esforço. É dessa forma contraditória, historicamente correspondente às variáveis presentes na economia política, que a transformação das linguagens, as alterações estilísticas, o aparecimento de novos gêneros artísticos encontram e garantem à arte uma materialidade concreta.

Todavia, no Brasil, a ausência de correspondência histórica entre a produção artística e o meio social encontra fundamento na constatação de que 
cada nova geração de artistas corresponde a um recomeço da trajetória da arte, alimentando a idéia de que não temos uma tradição de visualidade incorporada ao nosso ethos ${ }^{9}$. No caso brasileiro, a materialidade da arte somente pode ser pensada "em termos meramente psicológicos" (Venâncio Filho, 1980 , p. 24). Seria ocioso recuperarmos os numerosos exemplos que nos levam a acreditar nisso. De resto, basta lembrar que a arte colonial 'desapareceu' sob o peso do academicismo oficial, e que este 'desapareceu' sob a emergência modernismo, e assim sucessivamente, sem que qualquer um desses estágios produtivos deixasse vestígios de conhecimento no meio social10.

Não obstante, há pelo menos três décadas que o circuito de arte, através de seus agentes ideológicos'11, vem se esforçando para produzir um modelo discursivo para a trajetória da produção artística brasileira. O exame desse modelo exige que problematizemos em conjunto, ainda que sob a forma breve de indicações, algumas de suas principais 'demandas ideológicas' (Resende e Brito, 1980).

Para Resende e Brito, uma das principais demandas apresentadas pelo modelo discursivo do circuito de arte brasileiro atende pelo nome de 'arte brasileira'. Fomentada pela elite intelectual nacionalista de todos os matizes ideológicos, essa demanda tem a pretensão de naturalizar o conceito de uma arte representativa da realidade nacional. Tal demanda parte do pressuposto da existência de um projeto cultural nacional abrangente, com o qual estariam de acordo diferentes classes sociais. Contudo, ao mesmo tempo em que a demanda nacionalista avaliza artistas e obras a fim de encaixá-los no conceito 'arte brasileira', mantém compromissos com determinados esquemas de mercado (Resende e Brito, 1980).

Deve-se salientar que cabe a esses esquemas mercadológicos impor a sobredeterminação do conceito sobre a produção, restando a eles, portanto, a palavra final acerca das obras que serão oficialmente aceitas no acervo 'arte brasileira'. A contradição dessa demanda é evidente, notadamente que as suas intenções nada mais são do que a expressão hegemônica de uma classe, e que, da imposição de uma estética oficial, resulta uma arte cuja historicidade é meramente artificiall2.

Outra demanda ideológica importante apresentada pelo modelo discursivo do circuito de arte brasileiro e analisada por Resende e Brito (1980) atende pelo nome de 'vazio cultural'. O anúncio da existência de um 'vazio' ou lacuna identificada num determinado momento da vida cultural do país funciona como indicador da existência de uma 'tensão-limite' entre o passado recente e o aqui e agora. Decorre daí a imposição da mudança mediante a ocupação opositiva rápida, explosiva, vibrante, jovem, por assim dizer, 'nova' - uma nova geração, novos produtos, novos consumidores. De outra forma essa ocupação se faz na perspectiva de uma oposição a si mesma, tendo em vista a sua presumível obsolescência e o 'natural' aparecimento de 
algo mais novo ainda. Dessa maneira, todas as tensões se diluem na presença da novidade, justificando, em termos meramente psicológicos, a materialidade da arte na esfera social.

A essa altura o leitor certamente já teve a oportunidade de observar que as demandas ideológicas contidas no modelo discursivo do circuito de arte visam tanto a esclarecer o sentido e o destino da produção artística brasileira como a lhe assegurar uma dimensão histórica. Nesse modelo estão configuradas as bases hegemônicas do pensamento estético da burguesia brasileira, mediante o qual os agentes do circuito de arte realizam gestões no sentido da construção de um telos para aquela produção.

Tomando por empréstimo a definição de Rodrigues (1998, p. 130) que diz ser o telos "uma imagem construída pelo discurso hegemônico com o fito de se tornar uma meta a ser perseguida incansavelmente pelo conjunto da sociedade, conduzida pela classe que o elaborou", e que, no limite, a ele se impõe a necessidade da sua reconstrução permanente13, gostaria de salientar, nesse sentido, a força extraordinária que a demanda ideológica 'vazio cultural' adquiriu no discurso hegemônico dos anos 60-80, da mesma forma que, não por acaso, e menos ainda por coincidência, a demanda 'retomada' da produçãol4 adquiriu dos anos 90 até hoje. Para exemplificar sem esgotar o assunto, cito o aparecimento da chamada 'Geração 80', nas artes plásticas, e a produção cinematográfica dos anos 90 . Em ambos os casos, a questão enfrentada pelos agentes do circuito foi a de estabelecer uma correspondência conceitual entre a produção artística brasileira e o novo paradigma estético surgido, a partir do exterior, no âmbito das mudanças verificadas no padrão de acumulação capitalista. Apresentado pelos agentes do circuito como expressão maior do novo paradigma estético, o pós-modernismo se constituiria na meta a ser perseguida pela sociedade, ainda que do ponto de vista estrutural tal condição estivesse longe de ser alcançado pelo país.

No caso das artes plásticas, ainda nos anos 80, em meio ao debate que se travava para a democratização do país, ao anúncio da existência de um 'vazio' cultural decorrente do compromisso das linguagens então correntes com o passado, se seguiu o anúncio do surgimento de uma nova geração, sem compromisso algum, uma 'geração nada', conforme discursavam os agentes do circuito. É verdade que a meta pós-modernista foi inicialmente rejeitada por muitos setores da intelectualidade brasileira como sendo uma "importação indevida" (Hollanda, 1980). Entretanto, embalada pela mídia com slogans atraentes, a nova 'geração', a Geração 80, acabaria sendo assimilada, garantia do salto à frente dado pela arte no Brasil.

Embora seja impossível negar o estrago produzido no início dos anos 90 pela "canetada mortífera de Collor no coração da atividade cinematográfica nacional" (Biaggio apud Reis, 2001), o que se seguiu a partir daí ocorreu de forma semelhante ao que descrevemos anteriormente no circuito de artes 
plásticas. Apenas o nome mudou, de 'vazio' para 'retomada'. Na realidade, o cinema brasileiro jamais deixou o círculo vicioso 'falência-retomadafalência'. Conforme analisei em Cinema brasileiro e público: o que a educação tem a ver com isso? (2002c), o cinema brasileiro vive, desde a década de 20 , o drama de ter de enfrentar o cartel internacional de distribuidores que impedem o crescimento do público, e, por conseguinte o lucro e o progresso do cinema brasileiro. Mas não apenas isso, pois na medida em que o público é levado a buscar nos grandes jornais, e eventualmente na TV e no rádio, as informações sobre o cinema, nos quais predomina o caráter palpiteiro da chamada 'crítica cinematográfica', a tendência é de estigmatizarem gêneros e linguagens nascentes e/ou que sejam assumidamente experimentais 15 . Portanto, se é certo que no início dos anos 90 o uso do termo deu significado à corajosa iniciativa da diretora Carla Camuratti de produzir o filme Carlota Joaquina em condições adversas, não é menos verdadeiro que a recorrência sistemática à 'retomada' pelos agentes do circuito ampliou-lhe o espectro operativo. A partir de meados dos anos 90, 'retomada' passou a dar significado conceitual ao novo telos estético do cinema brasileiro.

Geradas a partir de interesses estranhos ao trabalho efetivo do artista com a linguagem, as 'mudanças' promovidas a partir do anúncio do 'vazio' ou 'retomada' cumprem a função tática de institucionalizar fenômenos gerados artificialmente com a finalidade de estabelecer o novo paradigma teleológico a ser alcançado e preenchido. Percebe-se, nesse sentido, que o objeto do anúncio do 'vazio' ou 'retomada' não é, de fato, a produção corrente, muito embora o discurso não possua um tensionamento legitimado socialmente, seja para descartá-lo como algo esgotado, seja para absorvê-lo como algo nascente, a verdadeira função da mudança a ser promovida é, tão-somente conservar intocável o sistema de arte. Nesse sentido, a demanda 'vazio' ou 'retomada' tanto reproduz a dissociação entre o trabalho e a práxis ontocriadora realizada pela burguesia brasileira, reduzindo tudo à idéia de um ato de vontade do 'gênio criador', como, no limite, ela prepara o terreno para as contrafações ('geração' disso, 'geração' daquilo), firmando o compromisso ideológico de deixar lacunas de compreensão da dinâmica cultural do país.

\section{O engodo competente: a estética na educação brasileira}

A expansão ilimitada do conhecimento humano sobre o mundo material e a prodigiosa contração planetária dos últimos cinqüenta anos pela ação dos meios de comunicação e pela telemática deram ao mundo no pós-modernismo um rosto mais completamente humano do que jamais visto. Como salienta Fredric Jameson (1996, p. 275), "resta muito pouco do que possa ser considerado 'irracional', no sentido mais antigo de incompreensível". E nesse 
sentido, a noção de que o valor de uso é equivalente ao consumo de um item qualquer na vida revela a extraordinária escala de humanização do mundo e indica o abandono da cultura como transcendência do homem face ao mundo natural.

Considerando o poderio e a estratégia de disseminação de um novo aparato cultural capitalista pautado por esse novo estatuto, o desafio brasileiro se torna ainda mais complexo. Os temas daí decorrentes não apenas atualizam o debate sobre as questões da natureza colonial da cultura e do nacional em nosso país como recolocam a questão da apropriação do conhecimento estético pelo trabalhador brasileiro, e de como este tem participado dos embates no campo simbólico e, no limite, resistido às ofensivas do capital.

Restam muito poucas dúvidas de que, há três décadas, o Brasil convive com o espectro de uma catástrofe ampliada. Neste período, entre planos econômicos nacionalistas de controle inflacionário e políticas neoliberais globais de expansão do consumo, as taxas de juros foram elevadas a níveis jamais imaginados, a remuneração do trabalho diminuiu, a renda da população se contraiu, o desemprego se tornou estrutural e os direitos dos trabalhadores e da cidadania foram flexibilizados. No mesmo período, a despeito do crescimento negativo da economia brasileira, os indicadores do mercado têm demonstrado um vertiginoso aumento dos lucros dos bancos e financeiras. No curso desses mesmos trinta anos, a concentração de renda e as desigualdades sociais no país aumentaram, mantendo, permanentemente, uma vergonhosa proporcionalidade.

De acordo com o Jornal do Brasil (2004), o economista Marcio Pochmann, atual Secretário do Trabalho da prefeitura de São Paulo, analisa a catástrofe que combina concentração de renda e expansão da pobreza como um "ciclo de 'financeirização' da riqueza", iniciado no início dos anos 80. Segundo a matéria do jornal, os dados reunidos pelo economista indicam que no curso de vinte anos "a base da pirâmide social ficou ainda maior com o esvaziamento da classe média, (...) sendo que os $1 \%$ mais ricos respondem por $75 \%$ do consumo familiar brasileiro, e que cinco mil famílias, sozinhas, são donas de $45 \%$ do PIB brasileiro, correspondendo a R \$ 691 bilhões" (2004, p. A19)16.

Feitas as contas do período, nenhuma relativização do sentimento 'catastrofista' que se abateu sobre a sociedade brasileira seria, portanto, capaz de dissimular a percepção da existência "de um desespero abafado se alastrando entre as pessoas" (Benjamin, 2003, p. 19).

No rastro desse quadro de indigência econômica, seguem a ética e a moral do país, demonstrando que não têm sido poucos, nem vãos, os esforços oportunistas empreendidos por uma parcela da intelligentsia no campo educacional brasileiro. Seja com a intenção de embaralhar conceitos com vista à flexibilização das posições políticas em disputa, seja com a intenção de 
corroer a matriz do pensamento progressista, essa espécie de caruncho intelectual cooptado pela burguesia empresarial se vale do prestígio político alcançado 'pela esquerda' nos embates contra o aparelho de Estado no tempo da ditadura militar para produzir, não sem uma elevada dose de cinismo, uma fraseologia mistificadora acerca da experiência concreta da educação brasileira 17. Nesta fraseologia, caracterizada pela prática denominada por Rodrigues de "metamorfoseamento teleológico" (1998, 130-133), termos inconciliáveis como, por exemplo, "cidadania" e "competitividade", são justapostos como necessariamente complementares.

Longe de ser um apanhado de idéias representativas do pensamento pedagógico empresarial exposto à disputa política, a fraseologia da intelligentsia neoliberal é o próprio corpo da Lei de Diretrizes e Bases da Educação Nacional. Detém, por isso, a força da documentação oficial da educação brasileira, como os PCNs, DCNs e toda a sorte de pareceres, e se define como o locus privilegiado das operações de adequação da educação brasileira às metamorfoses do telos empresarial18. Nesse sentido, é sintomático que o recente 'despertar' para o tema da estética no ensino politécnico voltado para a formação do trabalhador tenha sido pouco debatido em fóruns públicos e que tenha aportado emergencialmente nas DCNs. Seria ingenuidade supor que o interesse tenha sido estritamente pautado pela noção científica de objetividade no sentido de enriquecer o corpus pedagógico do ensino politécnico. Em poucas palavras, tal 'despertar' não é ideologicamente neutro. A esse propósito Giroux (1999), dentre outros, já havia observado que

\footnotetext{
“além das distorções ideológicas, do chauvinismo ocidental e do falso senso de igualdade e oportunidade que a educação freqüentemente legitima, é importante enfatizar que as escolas públicas e outros locais educacionais nunca são ideológica e politicamente inocentes" (Giroux, 1999, p.269).
}

De modo a concluir o presente ensaio, procurarei examinar brevemente dois exemplos eloqüentes do que acabei de expor: o Parecer 16/99 das Diretrizes Curriculares Nacionais para a Educação Profissional de Nível Técnico, do Conselho Nacional de Educação/Câmara de Educação Brasileira, e os Parâmetros Curriculares Nacionais, ambos documentos oficiais a regerem a educação brasileira desde meados dos anos 90.

Formulado à luz dos novos paradigmas educacionais ditados pelo modelo de competência, o Parecer 16/99 das Diretrizes Curriculares Nacionais para a Educação Profissional de Nível Técnico representa, dentre outras coisas, um tragicômico exercício de adequação conceitual da estética ao telos educacional do empresariado brasileiro sob o neoliberalismo. Seria por demais repetitivo e ocioso nos aprofundarmos no tipo de 'gongorismo pedagógico' utilizado pelos autores não fosse necessário, como diria Marx 
na Ideologia alemã (2000), apreciar o justo valor dessa charlatanice ou engodo competente.

Apresentada como um dos três princípios da educação profissional, a "estética da sensibilidade" se propõe a buscar "paradigmas axiológicos para (...) a prática institucional e pedagógica da educação profissional. Sua finalidade é definir a "identidade" e "especificidade" da educação de nível técnico, com vistas ao "desenvolvimento de competências para a laborabilidade, [e] à flexibilidade" (Brasil, 1999). De acordo com os autores do Parecer, a incorporação da "estética da sensibilidade" como um princípio da educação profissional se justifica por se inserir "em um contexto mais amplo que é o do respeito pelo outro". Acreditam que, no mundo contemporâneo, "a expansão da sensibilidade" é um item "imprescindível ao desenvolvimento pleno da cidadania".

Examinado isoladamente, o que parece ser um conjunto inofensivo de idéias preliminares a reproduzir o senso comum presente há décadas no pensamento educacional idealista na verdade prepara o terreno para a introdução da estética na imagem ou telos da educação profissional. Nesse sentido, ao recorrerem ao pleonasmo ("estética da sensibilidade") para "dar força à expressão", os autores do documento indicam as principais demandas ideológicas concernentes à "estética da sensibilidade" na educação do trabalhador: valores pautados nos "conceitos de qualidade e respeito ao cliente" e também no "desenvolvimento de uma cultura do trabalho centrada no gosto pelo trabalho bem feito e acabado". Não obstante a aparente neutralidade desses termos e expressões, eles não deixam margem para dúvidas acerca do caráter determinista da demanda ideológica "estética da sensibilidade".

Tal caráter pode ser verificado pelo conjunto de subordinações a que o documento faz referência, todas elas reproduzindo o conjunto de práticas laborativas exigidas no padrão de acumulação flexível. Nesse quadro, a “aquisição de laborabilidade" se subordina à 'aquisição' da sensibilidade quer para o trabalhador "intuir a direção dos novos padrões de qualidade", quer para identificar "nichos específicos de mercado para oferecer produtos ou serviços que sirvam a segmentos determinados de consumidores".

Não mais interessante nem menos tendenciosa do que o Parecer 16/99 é a proposta para o ensino de arte contida nos Parâmetros Curriculares Nacionais do MEC (Brasil, 1997). A seguir, reproduzo os principais pontos da análise que realizei em outro trabalho (Reis, 2003).

O primeiro ponto importante a ser considerado no documento é a justificativa da atualidade dos pressupostos teóricos do modelo curricular baseado fundamentalmente nos conceitos da 'arte-educação' apresentada no corpus do documento. Para isso, os autores fazem uma resumida abordagem crítica das teorias e das práticas que fundamentaram e embasaram, no século $\mathrm{XX}$, os movimentos, que, de um modo genérico, lutaram pelo ensino de 
arte na escola regular. Nesse sentido, situam os principais marcos históricos em três momentos distintos: a década de 1940, na qual despontou internacionalmente o movimento educação através da arte liderado por Hebert Read; o período compreendido entre os anos 60 e 70, palco do surgimento do movimento arte-educação nos EUA, marcado por uma intensa revisão crítica dos conceitos de 'arte infantil' e 'livre expressão' defendidos por Read; e o período de amadurecimento, compreendido entre os anos 80 e 90, no qual os princípios e propostas da arte-educação se abrem para uma visão mais genérica dos problemas da arte e da formação do indivíduo e, sendo assimilada institucionalmente, assume a denominação de ensino de arte.

A ausência de uma explicitação do cenário histórico, que, ao fundo, prepara as condições do processo de amadurecimento dos conceitos da arte-educação induz a que se pense que o desvio de enfoque dos arte-educadores norte-americanos sobre a questão do conhecimento artístico, das suas funções sociais e papel na formação do indivíduo se deu exclusivamente por força de uma oposição teórica ao modelo de Read e aos equívocos cometidos na aplicação desse modelo. O documento omite que a revisão crítica dos conceitos 'arte infantil' e 'livre expressão' — defendidos por Read — por parte dos arte-educadores norte-americanos se dava num contexto em que a crise do pensamento fundador já havia perdido densidade e a própria revisão não fazia mais sentido. De fato, se por um lado o legado de Read era um incômodo modernista para os educadores estruturalistas e cognitivistas; por outro lado, estes reconheciam que sua oposição fazia parte de um mesmo estatuto, no qual a arte era assinada pelo 'gênio'.

Penso que o problema dessa ausência de contextualização não seria tão grave caso o argumento dos autores pudesse sustentar, do ponto de vista da história, a afirmação de que a "descaracterização da área por longo tempo" se deveu ao "consenso pedagógico formado em torno do conceito de criatividade, jamais definido" e "à imprecisão e à aplicação de idéias vagas sobre a função da educação artística" (Brasil, 1997). Embora concorde pontualmente com a crítica ao consenso e à imprecisão, na verdade não consta que na prática as mudanças sugeridas tenham sido de fato adotadas, pois, na medida em que a discussão corrente no contexto da época não estava dissociada da própria crise experimentada pelo projeto modernista, dificilmente o caminho teórico proposto Read seria de todo abandonado. Para reforçar esse argumento chamo a atenção para a análise de Fredric Jameson (1996) sobre a ação do capitalismo na esfera cultural a qual teria engendrado no curso de meio século o esmaecimento da figura do sujeito-criador (o senhor da assinatura reificadora da obra de arte). Sua conclusão é de que esse esmaecimento resultou naquilo que ele denomina de “alívio do pós-moderno (...) no qual os vários rituais modernistas ficam deslocados e a produção da forma novamente se torna aberta para quem quiser se comprazer com ela" (1996, p. 317). 
Embora concorde com essa conclusão, observo que Jameson deteve-se apenas nos mecanismos econômicos e políticos, não atentando para a importância do processo educacional, particularmente a decisiva capacidade de o ensino de arte influenciar ideologicamente o imaginário social, como contribuinte para o surgimento desse 'alívio pós-moderno'. Ora, admitindo-se que nesse meio século sucessivas gerações de crianças e jovens, hoje adultos, tivessem adquirido os meios de se aliviarem dos valores formais do modernismo, parece-me lógico pensar que uma parcela significativa de arteeducadores norte-americanos não apenas manteve-se fiel ao espírito readniano da 'livre expressão' como adotou sistematicamente os seus conceitos.

O segundo ponto a ser considerado, a exposição da trajetória das lutas pela implantação do ensino de arte no Brasil decorre do anterior, pois, como já afirmei, os parâmetros curriculares têm como premissa básica os ideais do movimento Arte-Educação. Aqui os autores buscam historicizar seqüencialmente os períodos de emergência e vigência das lutas dos movimentos de arte-educadores no Brasil, detendo-se apenas na exposição dos programas curriculares, seus padrões e modelos, métodos de ensino, suas técnicas e objetivos, finalidades e aplicação, excluindo de todo modo a análise da questão do espaço social de legitimação histórica da arte a partir da transformação das linguagens.

A ausência de uma exposição sobre as condições concretas do aparecimento e desenvolvimento dos fatos que articulam e relacionam a trajetória do ensino de arte com o meio de arte nos termos expostos na primeira parte desse texto não apenas subtrai do senso comum a possibilidade de se esclarecer sobre o que seja o trabalho de arte e o que ele produz como obscurece a leitura que pretendem oferecer sobre o estatuto social da educação e da arte. Por conseguinte, evidencia-se no documento a visão de que a práxis artística é um dado natural, reforçando a mistificação em torno do processo da criação artística, do ato criador, da figura do 'gênio'.

O eixo ordenador do documento apresenta a arte como parte de um capital cultural acumulado previamente dado, no qual o papel histórico da arte na vida social reduz-se conceitualmente à noção 'vida-valor-arte'. Percebo isso primeiramente nessa perspectiva teleológica idealista e conservadora, que naturaliza o processo de 'criação' e do 'gênio' e silencia-se a respeito do trabalho de arte, e também na intenção dos autores de colocarem os objetivos da educação estética ao alcance de um certo tipo de humanismo motivado "por uma visão das artes, da cultura e na escolarização que pressupõe e legitima formas particulares de história, comunidade e autoridade" (Giroux, 1999, p. 268). Tal percepção leva-me a crer que o seu horizonte ideológico na verdade expressa uma orientação conservadora sobre os propósitos da educação estética no processo de formação do imaginário social e, mais do que isso, uma orientação reacionária quanto à idéia de cidadania como uma totalidade. 
Nesse sentido, sou obrigado a pensar no tipo de mudança a que se refere o documento. Pelo conjunto de sintomas apresentados parece-me do tipo - se me permitem o neologismo - lampedusina, isto é, para conservar tudo do mesmo modo. Ou, como prefere Florestan Fernandes, uma mudança que tanto pode servir para "despertar falsas esperanças e crença na transformação automática da sociedade" como para "vitalizar o conservantismo" (1986, p. 25).

Complementarmente, noto ainda duas motivações psicológicas que me parecem inexoravelmente interligadas. A primeira delas voltada para o público externo cuja origem se situa na tradição do pensamento conservador brasileiro de "fechar horizontes" (Fernandes, 1986) - tradição esta que tem levado as elites políticas a reagirem aos primeiros sinais de desconforto das massas com o status quo através da via clássica da antecipação (intervenção, golpes de Estado etc.) aos conflitos sociais, ou através de reformas como as que hoje são promovidas pela elite intelectual assentada no poder. Neste último caso, as reformas em curso - incluindo aquelas que deram origem às diretrizes curriculares em discussão - têm como objetivo estratégico confessável não apenas forçar a aceitação do país na ordem econômica global como, principalmente, fazer triunfar o homo aestheticus que nasce com a ideologia da pós-modernidade (Maffesoli, 1996). Já a outra motivação está voltada para o público interno, melhor dizendo, para a imagem que a intelligentsia faz do país e de si mesma; origina-se no sentimento de 'decadência' que ela nutre quer em relação ao povo e quer em relação à velha oligarquia política. Dessa forma, muito embora as reformas ou o 'mudancismo' alardeado sejam apresentados como uma estratégia para dirimir o 'atraso' de décadas, em verdade revelam-se objetivos inconfessáveis da intelligentsia, pois funcionam no sentido de sublimar a pressão que esta sente do sofrimento com a “decadência" (Freud, 1997) e para "conquistar posições de poder" (Fernandes, 1986). Como se observa, ainda aqui prevalece o lampedusismo, só que nesse caso sob a gestão de uma elite intelectual, e é essa visão empobrecedora do que seria a 'cultura cívica' 19 em nosso país que percebo dominante nas concepções pedagógicas de arte, de conhecimento artístico, de criação, de cultura e de educação estética nas diretrizes curriculares em questão. 


\section{Notas}

1 Professor Adjunto da Faculdade de Educação da Universidade Federal Fluminense e pesquisador do CNPq. Doutor em Comunicação pela Universidade Federal do Rio de Janeiro, com Pós-Doutorado em Educação. <ronaldo3@vm.uff.br> e <ronaldo.rosas@ig. com.br>.

2 Alexander G. Baumgarten (1714-1762) publicou o primeiro dos dois volumes de Aesthetica em 1750. Ao longo dos anos seguintes até 1758, ele revisaria este volume e publicaria o segundo. Baumgarten teve o mérito histórico de criticar, pela primeira vez, o empirismo que presidia o pensamento de Wollf, Hume, Berkeley, dentre outros contemporâneos seus, no qual a estética era caracterizada como um corpo de regras para a produção da obra de arte e um instrumento de análise dos seus efeitos psicológicos. Ele proporia, também de forma pioneira, a utilização do termo estética (do grego aisthesia, sensação, sensibilidade, sensível) para caracterizá-la como uma gnosiologia da sensação. Ou, por outra, uma teoria do conhecimento dos sentidos humanos (Reale e Antiseri, 1988, p. 694-695). Sobre este assunto, ver também Luria (1978).

3 Para uns, a autonomia da Estética perante a Filosofia e as demais Ciências Humanas seria conquistada na medida em que ela se firmasse como uma Ciência do Belo; para outros, como uma Ciência da Arte.

4 Kant, por exemplo, dizia que o prazer estético é "um prazer vazio, que contém em si a renúncia do prazer: é um prazer purificado do prazer". Para Kierkegaard, a dimensão estética é claramente negativa: a estética, que foi uma vez consumação da beleza, é agora sinônimo de fantasia ociosa e desejo degradado.

5 Sobre a metáfora da 'coruja de Minerva', que somente alça vôo no crepúsculo, fazendo referência à recusa do mundo sensível pelo olhar da filosofia e o olhar da ciência, ver Rodrigues (1999).

6 Sobre este assunto, ver Reis (2002b).

7 De anestético, do grego anaiesthesia, sem sensibilidade, em oposição à estesia, do grego aisthesia, sensação, sensível, sensibilidade, Ver nota 4.

8 Pode-se argumentar contrariamente a isso, como o fazem os críticos idealistas, que o 'belo' é um produto da consciência universal (a Idéia hegeliana, por exemplo), e que, portanto, o despertar humano para a arte decorre da subordinação desta àquela. Mas trata-se de uma visão hispostasiada da realidade, sendo, no limite, preguiçosa.

9 Como diz Lessa (2001, p. 159), "refesteladas no ócio pela fruição do trabalho escravo", a burguesia brasileira, desde os tempos coloniais, abriu mão do encontro de soluções criativas no seu processo histórico. Sua patológica aversão pelo trabalho vicejou a ponto de torná-la subserviente aos modismos importados, ensejando a dependência econômica da cultura do país, denominada por Glauber Rocha como "tradição de mendicância" (Rocha, 1985, p. 31). É necessário esclarecer, na linha do raciocínio de Carlos Nelson Coutinho (2000, p. 46), que "embora condicionado pela relação de dependência (ou de subordinação econômica), [o] vínculo com a cultura universal não impõe necessariamente um caráter dependente ou 'alienado' à totalidade da nossa cultura". 
10 Vale observar, a título de esclarecimento (e insistência), que o que diferencia esse aspecto do problema no Brasil do restante da América Latina e dos principais centros culturais nos EUA e na Europa não é tanto a existência de um mercado e muito menos o controle exercido por ele sobre a produção, mas sim o poder que os agentes ideológicos do mercado de arte brasileiro detêm de institucionalizá-la a partir da legitimação ou não da linguagem de determinada produção.

11 A forma do circuito de arte é determinada pelo mercado, dele fazendo parte tanto os agentes da circulação da obra (marchands, galeristas, colecionadores, leiloeiros, críticos, curadores, burocratas do serviço público, professores universitários, jornalistas-colunistas e repórteres encarregados da cobertura do circuito) quanto as instituições por onde ela circula (galerias, bienais, museus, centros culturais, universidades, páginas de jornais e da Internet, revistas, cd-rom). A simples constatação dessa circulação, isto é, de que as obras são apresentadas, cotadas e negociadas no circuito, não oferece garantia alguma de que tenham sido apropriadas pelo meio social sob a forma de conhecimento e que o trabalho artístico que as gerou seja reconhecido socialmente. Conforme diz Venâncio Filho (1980, p. 23), "são os níveis diversos de apropriações pelo meio social que determinam historicamente a sua real capacidade de promover a dimensão cultural de qualquer trabalho, e no caso da arte isso não se dá de forma diferente".

12 Cabe observar que a demanda ideológica por uma arte nacional tem-se feito à revelia da proposta estética do artista bem como de sua posição política no campo democrático. Na verdade, o que existe é uma forma de agenciamento ideológico, muitas vezes involuntário, a um projeto utópico - a união nacional, a brasilidade, a latinidade etc. — que pode servir tanto à luta contra a ditadura como a favor dela, como pode ser também utilizado, como faz o atual governo, para justificar a sua disfunção no campo da arte.

13 Para Rodrigues, a metamorfose teleológica se constitui "na construção e reconstrução, no discurso dos industriais, de sucessivos telos". Ainda segundo o autor, o caráter programático e estrutural do telos, permite que ele seja ajustável às novas configurações políticas surgidas na conjuntura ao mesmo tempo em que empresta "a todos os outros conceitos e propostas a eles subordinados também um caráter fundamentalmente econômico" (Rodrigues, 1998, p. 131)

14 Utilizada recorrentemente no discurso hegemônico dos agentes do circuito cinematográfico a partir dos anos 90, a expressão 'retomada da produção' esconde sua intenção verdadeira que é, senão outra, a de se opor ao padrão produtivo anteriormente adotado pelo setor cinematográfico brasileiro. Nesse sentido, ela se caracteriza como uma metamorfose conceitual do telos estético da burguesia. Sobre este assunto, ver, de minha autoria, Cinema brasileiro e público: o que a educação tem a ver com isso? Disponível em: <www.anped.org $>$.

15 Recorrendo a determinados mitos consolidados pela própria mídia em outras épocas, tais como a de que ao cinema brasileiro 'falta empatia', que tem uma 'narrativa difícil' de ser assimilada pelas grandes massas populares e que existe uma 'obsessão temática' dos realizadores por sexo, violência e miséria, as colunas que versam sobre cinema elidem o significado histórico da sua presença entre nós, condenando prematuramente jovens realizadores a uma espécie de limbo do mercado, do qual muitos dificilmente conseguem sair. Ver a nota anterior.

16 Ainda segundo a matéria do Jornal do Brasil (2004), os dados reunidos por Pochmann indicam que $50 \%$ das famílias mais ricas estão concentradas em quatro cidades, Rio de Janeiro, São Paulo, Belo Horizonte e Brasília, ganhando oitenta vezes mais do que as famílias mais pobres. 
17 Há tempos, autores como Frigotto (2000) vêm analisando criticamente o processo de resignificação conceitual da educação no âmbito do capitalismo tardio. Segundo este autor, o intenso processo de migração, empreendido por muitos intelectuais, dos marcos teóricos da tradição de esquerda para o confortável abrigo do espectro delirante da 'razão cínica' tem sido uma constante no campo educacional.

18 De acordo com Rodrigues, na medida em que a formação humana é reconhecida pelo empresariado como uma variável econômica, devendo, portanto, "ser fruto de um novo plano racionalmente construído", a lógica adequacionista se constitui, forçosamente, na perspectiva das novas "demandas do telos" (Rodrigues, 1998, p. 134).

19 A título de esclarecimento, a referência à 'cultura cívica' não propõe um resgate nostálgico das preocupações que motivaram os modernistas brasileiros - à maneira frankfurtiana da negatividade ou não-identidade - a fazer da arte acadêmica um território arrasado. Tampouco coincide com o projeto foucaultiano de se buscar formas de resistência culturais locais e específicas, mas predominantemente esteticistas. O que se propõe é uma diretriz para a educação estética com base na historicização do trabalho de arte, isto é, dos embates do produtor de linguagens à luz da natureza colonial e neocolonial da nossa cultura.

\section{Referências}

ARGAN, Giulio Carlo. 1990. Arte moderna. São Paulo: Martins Fontes.

BENJAMIN, César. 2003. Triunfo da razão cínica. Caros Amigos. Novembro. Disponível em <http://www.aconfraria.com. br/opiniao/cesarbenjamiml.htm $>$.

Acesso em : 1 set 2004.

BENJAMIN, Walter. 1985. Magia e técnica, arte e politica. São Paulo: Brasiliense.

BRASIL, 1997. Parâmetros Curriculares Nacionais - Arte. Brasília, DF: MEC/ SEF.

BRASIL, 1999. Parecer 16/99 das Diretrizes Curriculares Nacionais da Educação Profissional de Nível Técnico. Brasília, DF: $\mathrm{MEC} / \mathrm{CNE} / \mathrm{CBE}$.

BIAGGIO, Jaime. 2001. Crônica da geração perdida. O Globo, 6 ago., Segundo Caderno, p. 1-2.

COUTINHO, Carlos Nelson. 2000. Cultura e sociedade no Brasil: ensaios sobre idéias e formas. Rio de Janeiro: DP\&A.

EAGLETON, Terry. 1993. A ideologia da estética. Rio de Janeiro: Jorge Zahar.
FERNANDES, Florestan. 1986. A formação política e o trabalho do professor. In: CATANI, Denice Bárbara et al. (orgs.) Universidade, escola e formação de professores. São Paulo: Brasiliense, p.13-37.

FRANCO, Maria Ciavatta, RODRIGUES, José, FRIGOTTO, Gaudênci. 2000. Balanço e perspectivas. Niterói, RJ: Neddate. (Mimeo).

FREUD, Sigmund. 1997. O mal-estar da civilização. Tradução: José Octávio de Aguiar Abreu. Rio de Janeiro: Imago.

FRIGOTTO, Gaudêncio. 1999. Os delírios da razão: crise do capital e metamorfose conceitual no campo educacional. In: GENTILI, P. (org.) Pedagogia da exclusão. Petrópolis, RJ: Vozes, p. 77-79.

GIROUX, Henri. 1999. Cruzando a fronteira no discurso educacional. Porto Alegre: ArtMed.

HARDT, Michael; NEGRI, Antonio. 2001. Império. Rio de Janeiro: Record.

HOBSBAWM, Eric J. 1991. História social do 
jazz. São Paulo: Paz e Terra.

HOLLANDA, Heloísa B. (org.). 1980. Pós-modernismo e política. Rio de Janeiro: Rocco.

JAMESON, Fredric. 1985. Marxismo e forma. São Paulo: Hucitec.

1996. Pós-modernismo: a lógica cultural do capitalismo tardio. São Paulo: Ática.

JORNAL DO BRASIL. 2004. Brasil tem mais ricos. Jornal do Brasil, Rio de Janeiro, 2 abr., Caderno 1, p. A19.

KONDER, Leandro. 1967. Os marxistas e a arte. Rio de Janeiro: Civilização Brasileira. 2000. Os sofrimentos do 'homem burguês'. São Paulo: Senac.

KOSIK, Karel. 1995. Dialética do concreto. São Paulo: Paz e Terra.

LESSA, Carlos. 2001. O Rio de todos os Brasis: uma reflexão em busca da auto-estima. Rio de Janeiro: Record.

LURIA, Alexander Romanovich. 1978. Sensación y percepción. Barcelona: Fontanella.

MAFESSOLI, Michael. 1996. A tecnologia e a pós-modernidade: o reencantamento do mundo. Caderno de Pós-Graduação, v. 3, Rio de Janeiro: EBA/UFRJ, Programa de Pós-Graduação em História da Arte, p. 109-114. (Tradução: Rosza Vel Zoladz)

MARX, Karl; ENGELS, Friedrich.: 2002. A ideologia alemã. São Paulo: Martins Fontes.

1979. Sobre literatura e arte. São Paulo: Global.

REALI, Giovanni; ANTISERI, Dario, 1988. Historia del pensamiento filosófico y científico. Barcelona: Herder.

REIS, Ronaldo Rosas. 2002a. Do mundo objetivo ao mundo-objeto. Ciberlegenda, 3 . Disponível em: <www.uff.br/mestcii/ rep.htm>. Acesso em: 1 set. 2004. 2002b. O trabalho de arte e a arte do trabalho. In: CIAVATTA, M.; FRIGOTTO, G. (orgs.) A experiência do trabalho e o ensino básico. Rio de Janeiro: DP\&A, p.45-55.

2002c. Cinema brasileiro e público: o que a educação tem a ver com isso? Disponível em: <www.anped.org > .

2003. Educação e estética: ensaios sobre arte e formação humana no pós-modernismo. Rio de Janeiro: Mimeo. Inédito.

RESENDE, José; BRITO, Ronaldo. 1980. Mamãe Belas-Artes. In: DUARTE, P. S. (org.) Arte brasileira contemporânea, Caderno de textos 1. Rio de Janeiro: Funarte, p.29-31.

ROCHA, Glauber. 1985. Revolução do cinema novo. Lisboa: Alhambra.

RODRIGUES, José. 1998. O moderno príncipe industrial: o pensamento pedagógico da Confederação Nacional da Indústria. Campinas, SP: Autores Associados.

RODRIGUES, Neidson. 1999. Elogio à educação. São Paulo: Cortez.

SENNETT, Richard. 1989. O declínio do homem público: as tiranias da intimidade. Rio de Janeiro: Jorge Zahar.

VENÂNCIO FILHO, Paulo. 1980. Lugar nenhum: o meio de arte no Brasil. In: DUARTE, P. S. (org.) Arte brasileira contemporânea, Caderno de textos 1. Rio de Janeiro: Funarte, p.23-25.

Recebido em 12/04/2004

Aprovado em 14/05/2004 